\title{
Innate Resistance to Leishmania amazonensis Infection in Rat Is Dependent on NOS2
}

\author{
Yun-Fu Chen', Si-Fei Yu', Chang-You Wu², Na Wu', Jia Shen ${ }^{1}$, Juan Shen', \\ Jiang-Mei Gao', Yan-Zi Wen ${ }^{1}$, Geoff Hide ${ }^{3}$, De-Hua Lai ${ }^{1 *}$ and Zhao-Rong Lun ${ }^{1,3 *}$ \\ 'Guangdong Provincial Key Laboratory of Aquatic Economic Animals, Key Laboratory of Gene Engineering of the Ministry of \\ Education, State Key Laboratory of Biocontrol, School of Life Sciences, Sun Yat-Sen University, Guangzhou, China, ${ }^{2}$ Institute \\ of Immunology and Key Laboratory of Tropical Disease Control of the Ministry of Education, Zhongshan School of Medicine, \\ Sun Yat-Sen University, Guangzhou, China, ${ }^{3}$ Ecosystems and Environment Research Centre and Biomedical Research \\ Centre, School of Science, Engineering and Environment, University of Salford, Salford, United Kingdom
}

\section{OPEN ACCESS}

Edited by:

Esther Von Stebut,

University of Cologne, Germany

Reviewed by:

Mirian Nacagami Sotto,

University of São Paulo, Brazil Joao Luiz Mendes Wanderley, Federal University of Rio de Janeiro,

Brazil

*Correspondence: De-Hua Lai

laidehua@mail.sysu.edu.cn Zhao-Rong Lun

Iss/zr@mail.sysu.edu.cn

Specialty section:

This article was submitted to Microbial Immunology,

a section of the journal

Frontiers in Microbiology

Received: 30 June 2021 Accepted: 27 September 2021 Published: 29 October 2021

Citation:

Chen Y-F, Yu S-F, Wu C-Y, Wu N, Shen J, Shen J, Gao J-M, Wen Y-Z, Hide G, Lai D-H and Lun Z-R (2021)

Innate Resistance to Leishmania amazonensis Infection in Rat is Dependent on NOS2.

Front. Microbiol. 12:733286. doi: 10.3389/fmicb.2021.733286
Leishmania infection causes diverse clinical manifestations in humans. The disease outcome is complicated by the combination of many host and parasite factors. Inbred mouse strains vary in resistance to Leishmania major but are highly susceptible to Leishmania amazonensis infection. However, rats are highly resistant to $L$. amazonensis infection due to unknown mechanisms. We use the inducible nitric oxide synthase (Nos2) gene knockout rat model (Nos2 ${ }^{-/-}$rat) to investigate the role of NOS2 against leishmania infection in rats. Our results demonstrated that diversion toward the NOS2 pathway is the key factor explaining the resistance of rats against $L$. amazonensis infection. Rats deficient in NOS2 are susceptible to $L$. amazonensis infection even though their immune response to infection is still strong. Moreover, adoptive transfer of NOS2 competent macrophages into $\mathrm{Nos}^{-/-}$rats significantly reduced disease development and parasite load. Thus, we conclude that the distinct L-arginine metabolism, observed in rat macrophages, is the basis of the strong innate resistance to Leishmania. These data highlight that macrophages from different hosts possess distinctive properties and produce different outcomes in innate immunity to Leishmania infections.

Keywords: nitric oxide, Leishmania (L.) amazonensis, rat peritoneal macrophages, iNOS knock out, adoptive transfer

\section{INTRODUCTION}

Leishmaniasis, caused by Leishmania spp., is responsible for a wide spectrum of human diseases ranging from cutaneous leishmaniasis (CL), through mucocutaneous leishmaniasis (MCL) to the fatal form of visceral leishmaniasis (VL; Murray et al., 2005). It is endemic in 98 countries rendering approximately 350 million people at risk of infection worldwide (World Health Organization, 2010). Leishmania species are obligate intracellular protozoan parasites in the mammalian host and reside as aflagellated amastigote forms that primarily infect phagocytes, but exist as flagellated promastigotes in the gut of infected sandflies (Kaye and Scott, 2011).

The outcome of leishmaniasis is governed by both host and parasite factors (Alexander et al., 1999; Kaye and Scott, 2011). Experimental models of leishmaniasis have provided a 
large amount of useful data which have helped to elucidate the host immune defense mechanism against infection. Mouse models have been extensively exploited to investigate the host factors that might be responsible for resistance or susceptibility to infection. For instance, most inbred mouse strains are highly susceptible to L. amazonensis infection (Barral et al., 1983; Calabrese and da Costa, 1992; Soong et al., 1997). However, the best recognized model is the Leishmania major model of cutaneous leishmaniasis where inbred strains of mice vary in their ability to control L. major infection. For example, in $\mathrm{BALB} / \mathrm{c}$ mice, susceptibility is due to the development of a dominant type 2 helper T-cell (Th2) suppressive immune response, while in resistant $\mathrm{C} 57 \mathrm{BL} / 6$ mice, they are able to mount an effective Th1 response. This means that host resistance/ susceptibility is influenced by expansion of distinct helper T-cell subsets that are followed by the production of divergent cytokine profiles and macrophage function (Muller et al., 1989; Sacks and Noben-Trauth, 2002). Macrophages comprise the majority of Leishmania-infected cells and are the main effector cells that decide the fate of intracellular amastigotes. In the context of a Th1 response, macrophage inducible nitric oxide synthase (NOS2) is activated to produce nitric oxide (NO), resulting in the destruction of intracellular amastigotes. However, in the Th2 response, alternatively activated macrophages upregulate arginase expression that suppresses NOS2 activity and leads to uncontrolled parasite proliferation (Liew et al., 1991; Stenger et al., 1994; Wei et al., 1995; MacMicking et al., 1997). The hamster model is another frequently used model for leishmaniasis because it has clinical manifestations that closely mimic that of humans. Hamsters are highly susceptible to Leishmania infection due to the lack of a binding sequence for nuclear factor interleukin-6 (NF-IL-6) within the Nos2 promoter, rendering it refractory to activation by IFN- $\gamma / \mathrm{LPS}$, and resulting in impaired NOS2-mediated intracellular killing (Melby et al., 2001; Perez et al., 2006; Saldarriaga et al., 2012).

In a remarkable contrast to mice and hamsters, rats (Rattus rattus and others) in the laboratory are highly resistant to Leishmania infection (Giannini, 1985). Rats are frequently used as animal models in many biological studies (e.g., physiology, transplantation, medicine, and cancer) as they differ in many aspects when compared with mice. Very limited experimental work has been reported on the use of rats for investigating Leishmania infection. In the choice of an animal model to investigate host immune defense mechanisms against pathogens, the rat model is usually overlooked in favor of the mouse model. This probably results from the following facts: 1 . Mice are generally susceptible to many infectious agents and easy to establish infection. 2. Transgenics and knockouts in mice are generally easy to produce, and there are multiple genetically engineered mice that are already available worldwide. 3 . Immunological reagents and tools are readily available for mice while somewhat limited in rats. However, rats are generally more resistant than mice to many pathogen infections - thus offering an opportunity to explore mechanisms of resistance. This host difference is commonly, and traditionally, explained by host specificity but generally these explanations lack a clearly identified factor or process. It suggests that there should be striking differences in the immune response (innate or adaptive) between rats and mice during pathogen infection. Therefore, elucidation of the mechanisms of rat resistance to pathogen infection would provide an important impact on our understanding of the differences in the innate immunity between rats and mice.

In this study, a rat model of Leishmania amazonensis infection has been used to investigate the rat determinants that drive resistance to Leishmania infection. Leishmania is an obligate parasite that infects macrophage lineages, thus providing an excellent model to focus on macrophage function during infection. L. amazonensis was chosen because it is one of the most virulent species in the genus Leishmania and possesses powerful mechanisms to subvert the host protective immune response (Soong, 2012). In this work, we demonstrate that rat macrophages possess a significantly different L-arginine metabolism from mouse macrophages. This is characterized by the predominant usage of L-arginine by the NOS2 pathway, which confers strong resistance to Leishmania infection.

\section{MATERIALS AND METHODS}

\section{Animals}

Female Sprague Dawley (SD) rats, BALB/c mice, and C57BL/6 mice were purchased from Zhongshan School of Medicine, Sun Yat-Sen University (SYSU), Guangzhou. Female Nos $2^{-1-}$ SD rats were generated by TALENs and bred in the animal facility of SYSU (Shen et al., 2017). All the animals were maintained in specific pathogen-free conditions. Protocols for the use of animals were approved by the Institutional Review Board for Animal Care at Sun Yat-Sen University (NO:31472058).

\section{Antibodies and Reagents}

Monoclonal antibodies used for phenotypic and intracellular cytokine analyses: isothiocyanate (FITC)-anti-CD3, PE-Cy7labeled anti-CD4, and peridinin-chlorophyll protein (PerCP)labeled anti-CD8 were purchased from BD Biosciences (San Jose, CA). Rat ELISA kits for cytokine IFN- $\gamma$ and IL-4 were purchased from BD Biosciences.

\section{Parasites and Culture}

Leishmania amazonensis LV78 (RAT/BA/74/LV78) causes only cutaneous infection, a clone expressing enhanced green fluorescent protein (eGFP) was kindly provided by Dr. K. P. Chang. This parasite showed no difference in infection virulence to macrophages or mice compared to the wildtype strain (Chan et al., 2003). The amastigotes of the LV78 strain were freshly isolated from footpad lesions of previously infected $\mathrm{BALB} / \mathrm{c}$ mice and transformed into promastigotes in Schneider's insect medium (SDM, pH 6.9) supplemented with $10 \%$ FBS (Hyclone) at $26^{\circ} \mathrm{C}$. The parasites at stationary phase (day 5 culture) were used for in vitro or in vivo infection. Only 2 to 9 passages were used in subculture of the parasites in order to make sure that virulence of the parasites was maintained for infection. 


\section{Isolation of Peritoneal Macrophages and Infection With Leishmania}

Naïve peritoneal macrophages were isolated by peritoneal lavage with ice-cold D-hanks buffer as described preciously ( $\mathrm{Li}$ et al,, 2012). Briefly, WT and $\mathrm{Nos}^{-/-}$rats (females, 9 weeks old) were sacrificed by $\mathrm{CO}_{2}$ asphyxia. A total of $20 \mathrm{ml}$ ice-cold D-hanks buffer were injected into the peritoneal cavity and then withdrawn. Cells were collected by centrifugation and resuspended in RPMI1640 (without phenol red) supplemented with 10\% FBS and 100 U/ $\mathrm{ml}$ penicillin and streptomycin. Then, $5 \times 10^{5}$ macrophages were seeded into each well of a 24 -well plate with $500 \mu$ l medium. Four hours later, unattached cells were removed by washing twice with pre-warmed D-hanks buffer to obtain macrophages. Macrophages were allowed to culture overnight before infection. LV78 promastigotes from stationary culture were washed 3 times in D-hanks buffer, resuspended in complete RPMI-1640 medium, and adjusted to a final concentration of $2.5 \times 10^{7}$. Aliquots of $100 \mu \mathrm{l}$ were put into each well of a 24-well plate with a ratio of parasites to macrophages of 5:1. They were then incubated at $35^{\circ} \mathrm{C}$ with $5 \% \mathrm{CO}_{2}$ for $6 \mathrm{~h}$, and free promastigotes were removed by washing 3 times with pre-warmed D-hanks. Cells were treated with or without various combinations of IFN- $\gamma(50 \mathrm{ng} / \mathrm{ml})$ and aminoguanidine (AG, $5 \mathrm{mM}$ ). Culture supernatants were collected at indicated time points to determine the production of NO. At $0,24,48$, and $72 \mathrm{~h}$ postinfection, and parasite proliferation was determined by counting at least 300 macrophages to enumerate the percentage of cells infected and amastigotes per 100 macrophages.

\section{Determination of Nitric Oxide Production}

Culture supernatants were collected from treated cells. Proteins were removed by adding $\mathrm{ZnSO}_{4}$ to a final concentration of $30 \mathrm{mg} / \mathrm{ml}$, and the liquid was thoroughly vortexed and centrifuged at $8,000 \mathrm{~g}$ for $10 \mathrm{~min}$. Then, $100 \mu \mathrm{l}$ of total supernatant was mixed with $100 \mu \mathrm{l}$ Griess reagent and incubated in the dark for $10 \mathrm{~min}$; the absorbance was read at $540 \mathrm{~nm}$, and nitrite concentrations were calculated against a standard curve.

\section{Determination of Arginase Activity}

Arginase activity of macrophages was measured by a colorimetric method as described (Corraliza et al., 1995). Ten mm $\mathrm{MnCl}_{2}$ and $0.5 \mathrm{ML}$-arginine were successively added to macrophage lysates for $1 \mathrm{~h}$ at $37^{\circ} \mathrm{C}$. The reaction was stopped by addition of an acid solution $\left(\mathrm{H}_{2} \mathrm{SO}_{4}: \mathrm{H}_{3} \mathrm{PO}_{4}: \mathrm{H}_{2} \mathrm{O}=1: 3: 7\right)$, and the urea generated by arginase was analyzed by addition of a-isonitrosopropiophenone at $100^{\circ} \mathrm{C}$ for $45 \mathrm{~min}$. The colored product was quantified by absorption at $550 \mathrm{~nm}$ in an ELISA reader. Arginase activity was determined as the amount of urea produced from total protein of peritoneal macrophages.

\section{Infection of Animals and Determination of Lesion Development}

Groups of WT, heterozygous (Het), and $\mathrm{Nos}^{-/-} \mathrm{SD}$ rat $(n=12$, in each group, 4 weeks old) were subcutaneously infected in the left ear with $10^{7}$ stationary phase L. amazonensis LV78 promastigotes, using a $30 \mathrm{G}$ needle, in a volume of $10 \mu \mathrm{l}$ PBS, while the control rat ear received $10 \mu \mathrm{PBS}$ without parasites.
Uninfected rats of the same age were used as controls. The lesion thickness and diameter were measured every 4 or 8 days with a dial caliper. Lesion thickness was calculated by subtracting the thickness of the control ear from the infected ear, while lesion diameter was measured as the longest axis of the ear lesion.

\section{Estimation of Parasite Load by Limiting Dilution Assay}

At 32 and 64 days postinfection, 3 rats per group were sacrificed and the parasite load in the infected ears was estimated by using a limiting dilution assay as previously described with modification (Belkaid et al., 2000). Briefly, the infected ears were cutoff, and their surfaces were disinfected in $70 \%$ ethanol, and the dorsal and ventral part of the ear were separated with forceps. The two ear leaflets were placed dermal side down on SDM containing $1 \mathrm{mg} / \mathrm{ml}$ collagenase 1 (Sigma) and digested for $2 \mathrm{~h}$ in $37^{\circ} \mathrm{C}$. Then, the dermal sheets were cut into small pieces and homogenized in a glass tissue homogenizer with $2 \mathrm{ml} \mathrm{SDM}$ followed by the liquid being passed through a $70 \mu \mathrm{m}$ cell strainer (Falcon, BD) to obtain a single cell suspension. Serial 10-fold dilutions were made with SDM supplemented with $10 \%$ FBS and 5\% defibrinated rabbit whole blood lysate, and aliquots of $100 \mu \mathrm{l}$ were distributed in 96-well plates with 12 wells per dilution. The plates were kept at $26^{\circ} \mathrm{C}$ for up to two weeks, and the number of parasites was determined by the highest dilution for which the parasites could be grown.

\section{Histopathology}

Infected ears were collected and fixed in $4 \%$ paraformaldehyde for $24 \mathrm{~h}$. They were dehydrated with gradient solutions of ethanol and embedded in paraffin. The tissue specimens were sliced to a thickness of $5 \mu \mathrm{m}$ and stained with hematoxylin and eosin. All histological sections were observed by light microscopy (Leica DM 2500B, Germany).

\section{Preparation of Soluble Leishmania Antigen}

L. amazonensis LV78 promastigotes were grown to stationary phase in SDM and were collected and washed three times in PBS and then resuspended in PBS at $10^{9} / \mathrm{ml}$. The cells were subjected to 10 cycles of rapid freezing $\left(-70^{\circ} \mathrm{C}\right)$ and thawing at $\left(37^{\circ} \mathrm{C}\right)$ for lysis and centrifuged at $12,000 \mathrm{rpm}$ at $4^{\circ} \mathrm{C}$ for $10 \mathrm{~min}$, and the supernatants were then collected and passed through a $0.20-\mu l$ filter assembly. The protein concentration was determined by a BCA kit. SLA was stored at $-70^{\circ} \mathrm{C}$ until use.

\section{Analysis of Immune Cell Responses}

At 32 days postinfection, immune cells from Leishmania-infected WT and Nos2 $2^{--}$SD rats were isolated for analysis. PBMCs were isolated by Ficoll-Hypaque (Tianjin Hao Yang Biological Manufacture, Tianjin, China) density gradient centrifugation. Briefly, cells were suspended in Hank's buffer and gently added on top of the Ficoll solution, and the ratio of cell suspension to Ficoll was $4: 3$ and centrifuged at a speed of $2,200 \mathrm{rpm}$ for $20 \mathrm{~min}$. The cells in the second upper layer were harvested for mononuclear leukocytes and washed twice with D-Hanks. Spleen and lymph nodes cells were separated by traditional methods. Briefly, the 
spleens and mesenteric lymph nodes from rats were mashed to release the cells and they were then passed through a $70 \mu \mathrm{m}$ cell strainer to obtain single cells. Red blood cells were removed using ammonium chloride as a lysing reagent, and immune cells were then washed with D-Hanks buffer and resuspended in RPMI1640 supplemented with 10\% FBS. Cells were counted and seeded into each well of a 96-well plate with $2 \times 10^{5} \mathrm{cell} / \mathrm{ml}$. Cells were stimulated with SLA $(25 \mu \mathrm{g} / \mathrm{ml})$ for $48 \mathrm{~h}$. IFN- $\gamma$ and IL- 4 production in the supernatants were determined by ELISA.

\section{Cytokine ELISA}

Supernatant from SLA-stimulated cells were assayed for IFN- $\gamma$ and IL-4 with rat ELISA kits (BD Biosciences). Absorbances were read at $405 \mathrm{~nm}$ using a microtiter plate reader. Concentrations were determined using standard curves for each cytokine. The detection limits of IFN- $\gamma$ and IL-4 assay kits were 31.25 and $1.6 \mathrm{pg} . / \mathrm{ml}$, respectively.

\section{Serum Cytokine Analysis}

Rat serum was collected at 16,48 , and 64 days postinfection, and cytokines were analyzed by Multiplex Luminex using ProcartaPlex Rat Th Complete Panel (ProcartaPlex, eBioscience), according to the manufacturer's instructions.

\section{Isolation of Rat Bone Marrow-Derived Macrophages and Transfer to Infected Nos2 ${ }^{-/-}$Rats}

Bone marrow-derived macrophages (BMDMs) were generated as previously described with modification (Boltz-Nitulescu et al., 1987). Briefly, bone marrow cells were obtained by flushing femurs of adult SD rats with D-Hanks buffer, cells were then dispersed by passing through a needle, and erythrocytes were removed by lysis with $0.015 \mathrm{M}$ Tris- $\mathrm{NH}_{4} \mathrm{Cl}$ ( $\mathrm{pH}$ 7.4). The cells were then washed and resuspended in DMEM supplemented with $10 \%$ FBS and 30\% L929 cell supernatant. The cells were cultured in a $75 \mathrm{~cm}^{2}$ TC flask for 3 days with a change in fresh medium for another 4 days. Then, the BMDMs were harvested by digestion with $0.5 \%$ trypsin containing $0.03 \%$ EDTA. The harvested BMDMs were washed 3 times in PBS and adjusted to $10^{7}$ cells $/ \mathrm{ml}$ in PBS. The cells were i.v. injected into the recipient $\mathrm{Nos}^{-/-}$rat at $0,8,16$, and 24 DPI.

\section{Statistical Analyses}

Statistical differences between groups were analyzed with Student's $\mathrm{t}$ test using a built-in module of GraphPad Prism v5.0 (GraphPad software), using $p<0.05$ as the level of significance.

\section{RESULTS}

\section{NOS2 Activity Is Essential for Rat Peritoneal Macrophage Resistance Against $L$. amazonensis Infection}

To investigate the mechanism of rat resistance against Leishmania infection, macrophages were targeted since they play a crucial role in the host innate immune response and are the major cell type inhabited by Leishmania during infection (Rittig and Bogdan, 2000). Naïve peritoneal macrophages were isolated from mice and Sprague Dawley (SD) rats and infected with L. amazonensis in vitro. In accordance with previous studies (Giannini, 1985; Soong et al., 1997), macrophages from both $\mathrm{BALB} / \mathrm{c}$ and $\mathrm{C} 57 \mathrm{BL} / 6$ mice are susceptible to L. amazonensis infection as indicated by unrestrained intracellular parasite replication during infection and by NO being absent in the culture supernatant (Figures 1A,D). In contrast, macrophages from SD rats showed restrained L. amazonensis growth, with intracellular amastigotes remaining low and only showing a slight increase at $72 \mathrm{~h}$ postinfection (HPI). A considerable amount of $\mathrm{NO}$ was detected in the culture supernatant (Figures 1A,D). Nitric oxide (NO), produced by NOS2, has been shown to be the key antimicrobial agent found in macrophages, and its induction is critical in the control of many intracellular pathogens (Li et al., 2012). Therefore, we tested whether NO is important for conferring resistance to Leishmania infection in rat macrophages by inhibition of NOS2 activity with a specific inhibitor aminoguanidine (AG; Griffiths et al., 1993). When NOS2 was inhibited by AG, NO was not detected and parasite replication increased significantly, suggesting that NOS2 activity is indispensable in resistance (Figures 1A,D). To further dissect the role of NOS2, we generated an Nos2 gene knockout SD $\left(\mathrm{Nos}_{2}{ }^{-/-}\right)$rat using transcription activatorlike effector nuclease technology (TALENs; Tesson et al., 2011). TALENs resulted in a two-nucleotide deletion in the open reading frame of the Nos2 gene (Supplementary Figure 1A). Disruption of the Nos2 gene was demonstrated by the absence of NOS2 proteins in naïve or activated peritoneal macrophages and the absence of NO production in the culture supernatant of the activated macrophages (Supplementary Figures 1B,C), while arginase activity showed no significant difference between the wild-type and Nos $2^{-1-}$ macrophages (Figure 1F). Macrophages from $\mathrm{Nos}^{-/-}$rats showed a significant increase in parasite burden compared to the macrophages from the wild-type rats at $72 \mathrm{~h}$ postinfection (HPI; Figure 1C). More importantly, they failed to eliminate amastigotes even in the presence of IFN- $\gamma$, unlike the macrophages from the wild-type rats (Figures 1B,C). These observations clearly demonstrate that the parasite growth in NOS2 inhibited wild-type or Nos2 $2^{-/-}$macrophages was caused by the lack of NO production (Figure 1). The slight reduction in the parasite burden in the $\operatorname{Nos}^{-/-}$rat macrophages after IFN- $\gamma$ activation indicates that NO-independent killing of L. amazonensis might exist. However, it must play a minor role, since most of the parasites remain intact, indicating that $\mathrm{NO}$ is the predominant leishmanicidal effector in rat peritoneal macrophages.

\section{Rats Lacking NOS2 Lose Innate Resistance to $L$. amazonensis Infection and Develop Progressive Lesions}

The above results demonstrate the critical role of NOS2 for rat macrophage resistance against L. amazonensis infection in vitro. We employed a rat ear cutaneous infection model to further investigate the role of NOS2 in vivo. Wild-type (WT), heterozygous (Het), and Nos2 $^{-/-}$SD rats $\left(N o s 2^{-/-}\right)$were subcutaneously infected 


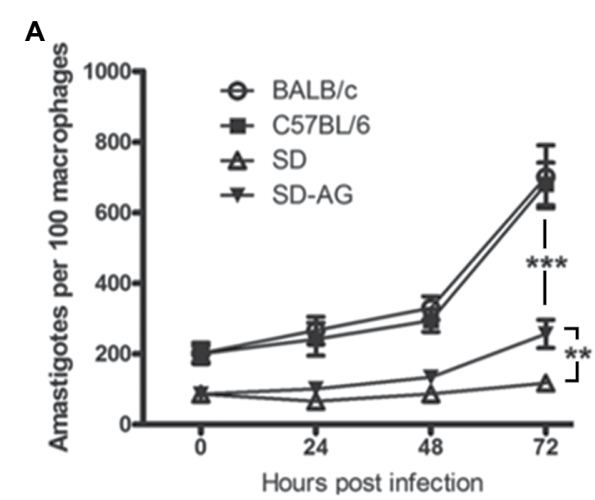

D

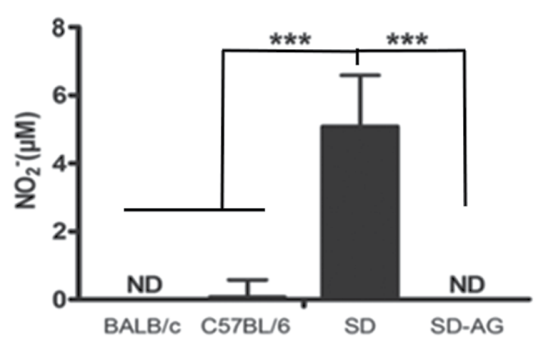

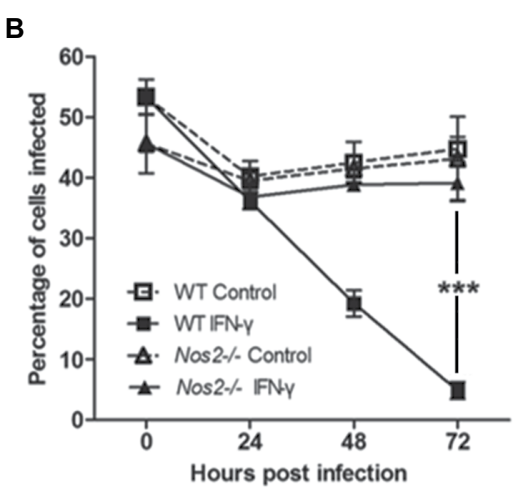

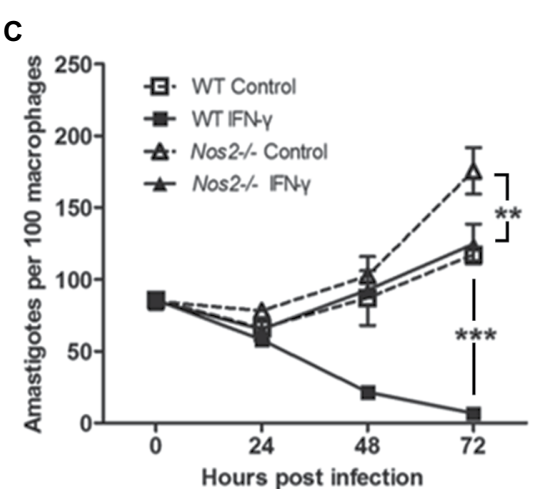

E

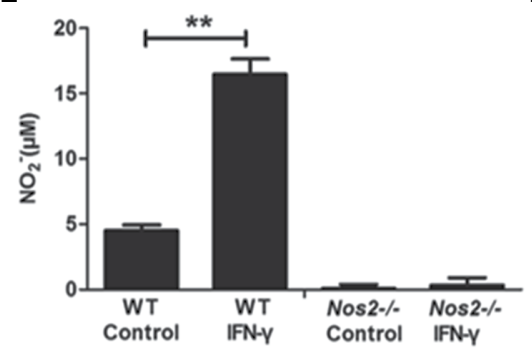

$\mathbf{F}$

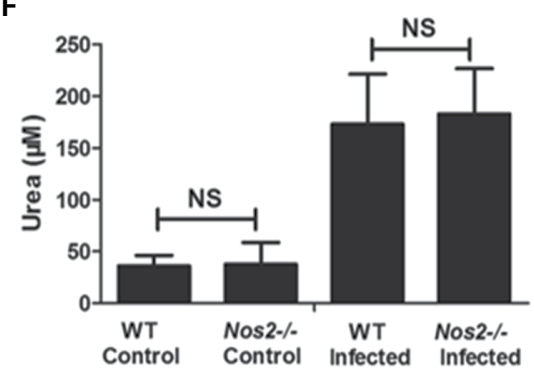

FIGURE 1 | NOS2 activity is indispensable for rat macrophage resistance to $L$. amazonensis infection in vitro. A,C, Peritoneal macrophages from BALB/C, C57BL/6 mice, wild-type SD rats (SD, WT), or Nos2 ${ }^{-/-}$SD rats $\left(\right.$Nos2 $\left.^{-/-}\right)$were incubated with L. amazonensis promastigotes, with $5 \mathrm{~mm}$ aminoguanidine (AG) or $50 \mathrm{ng} / \mathrm{ml}$ recombinant rat IFN- $\gamma$, if indicated. The number of amastigotes per 100 macrophages $(\mathbf{A}, \mathbf{C})$ and percentage of macrophages infected $(\mathbf{B})$ were shown. (D,F), Corresponding NO production (D,E) and urea production (F) in culture supernatants at $24 \mathrm{~h}$ postinfection were determined. The data (mean \pm SD amastigotes per macrophage) were derived from a single representative of three independent experiments. ${ }^{* *}$ indicates a significant difference $(0.001<P<0.01)$, ${ }^{* \star \star}(P<0.001)$.

with $10^{7}$ stationary phase promastigotes of L. amazonensis. Interestingly, the results showed that all the $\operatorname{Nos}^{-1-} \mathrm{SD}$ rats were highly susceptible to L. amazonensis infection compared to their wild-type SD and Het counterparts. In all Nos $2^{-/-}$rats, lesions began to appear at 8 days postinfection (DPI). Afterward, the lesions became progressively worse as shown by an increase in thickness and diameter. The increase in lesion pathology (thickness and diameter) occurred rapidly from 8 to $40 \mathrm{DPI}$, then levelled off, and did not show any sign of recovery (Figures $2 \mathbf{A , B}$ ). In contrast to mouse strains and Nos $2^{-/-}$rats, the resistance to infection in wild-type SD rats was demonstrated by observing only a temporary mild swelling or even absence of swelling, in some animals, during the course of the experiment. At the end of the experiment (56-64 DPI), no lesions were found in any WT rats. Het rats developed moderate lesions at the early stages of infection but were also able to heal afterward. HematoxylinEosin (HE)-stained sections of ear lesions at 32 DPI revealed

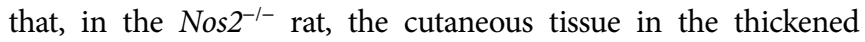
ear was dominated by an increased infiltration of inflammatory cells. However, unlike observations in mice (Vasconcellos and Sotto, 1997), granulomas were not observed at the site of the infection in rats even though there was extensive cell infiltration. Furthermore, the general structure of the ear was not affected.

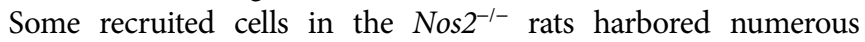
amastigotes, indicating their inability to kill parasites
(Figures 2D,E,G). In sharp contrast, the structure of the dermal tissue from the ear of wild-type rats remained either normal at 32 DPI or with a few cells infiltrating if mild swelling was present. However, we were unable to observe any amastigotes in the sections of WT ears, indicating that most of the injected parasites were eliminated (Figures 2D,F). The parasite burden of infected ears was estimated at 32 and 64 DPI, by a limiting dilution assay. The parasite load in lesions was much higher in Nos $2^{-1-}$ rats than in the wild-type and Het rats. At $32 \mathrm{DPI}$, parasite load in the $\mathrm{Nos}^{-/-}$rats was almost 330 -fold greater than that observed in WT rats. Furthermore, the parasite burden declined rapidly to an undetectable point in WT rats at $64 \mathrm{DPI}$ while it persisted in $\operatorname{Nos}^{-1-}$ rats. The parasite load in the Het rats was higher than that observed for WT rats at $32 \mathrm{DPI}$ $(p=0.027)$, but they were almost eliminated at 64 DPI (Figure 2C). The above results demonstrate that NOS2 was also indispensable for rat innate resistance to L. amazonensis in vivo.

\section{Rats Lacking NOS2 Present Normal Leishmania-Induced Specific Immune Responses After Infection}

The above results have shown that NOS2 plays a pivotal role in rat resistance against Leishmania infection, both in vitro and in vivo. Since NO has been shown to participate in both antimicrobial 


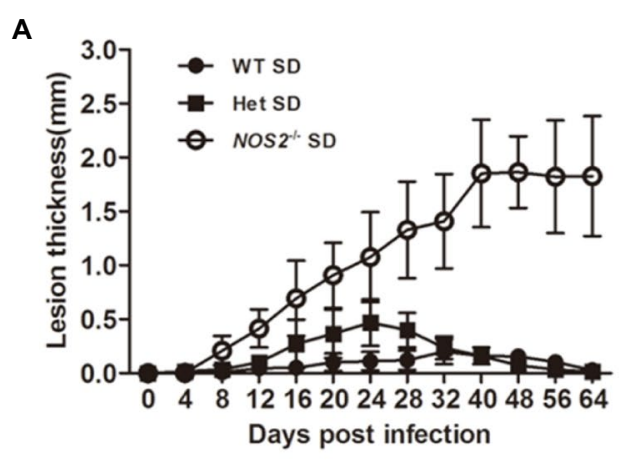

C

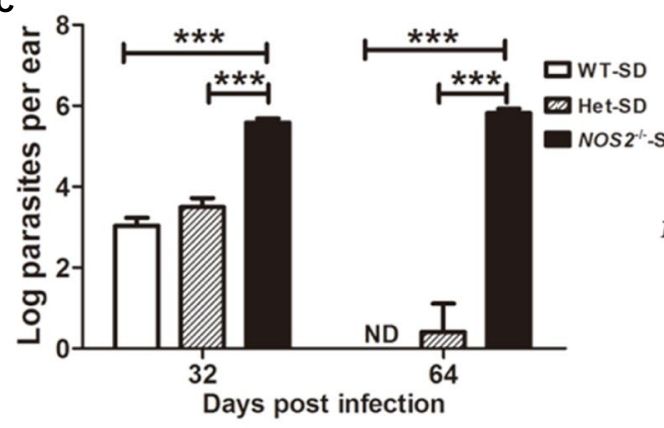

$E$
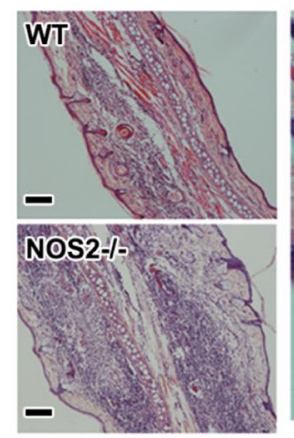

$\mathbf{F}$

\section{B}

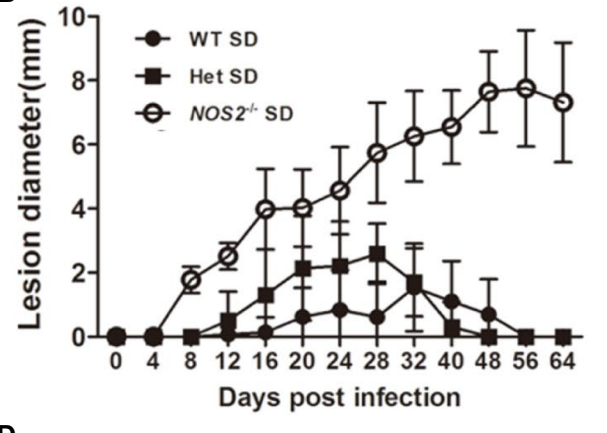

D
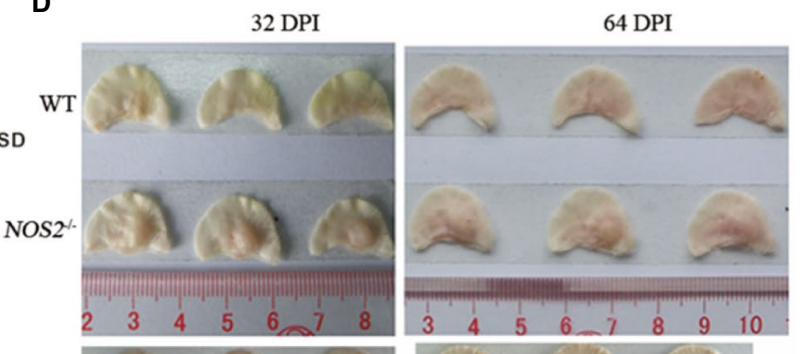

Het
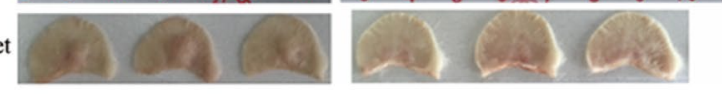

G
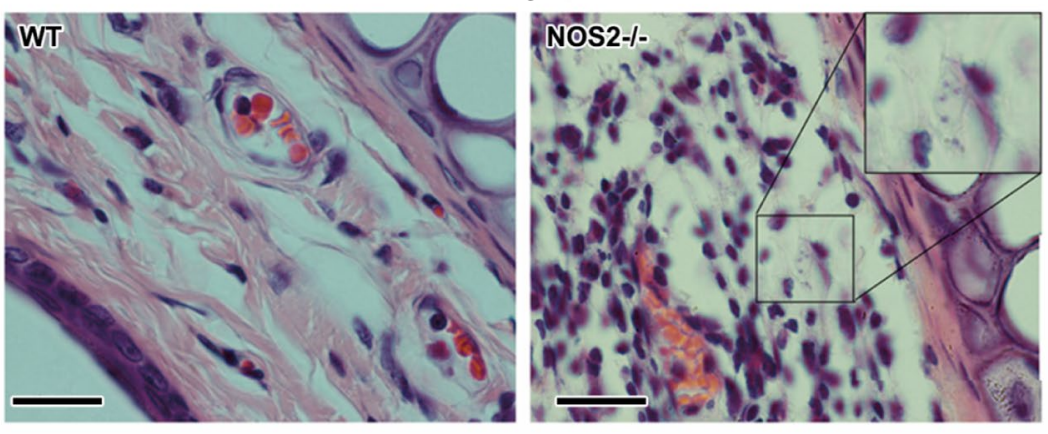

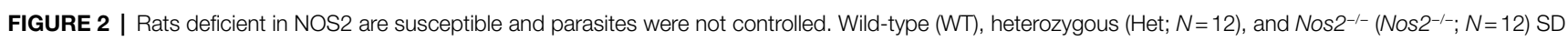
rats were subcutaneously infected with $10^{7} \mathrm{l}$. amazonensis LV78 in the left ear. Lesion thickness (A), and diameter (B) were shown as mean \pm SD. 0-32 days postinfection (DPI), $N=12 ; 40-64 \mathrm{DPI}, N=6$. The parasite load (C) in the lesion was determined by limiting dilution assay $(N=3$, mean $\pm S D)$. The outlook of representative infected ears (D). (E-G), HE-stained sections of infected ear at $32 \mathrm{DPI}$. Inset in G shows multiple amastigotes. Scale bar, $20 \mu \mathrm{m}$. ND: not detectable $(<20) .{ }^{* \star \star}$ indicates a significant difference $(P<0.001)$.

activity and immune regulation in mice (Taylor-Robinson et al., 1994; Diefenbach et al., 1999), it is important to know whether rats deficient in NOS2 are capable of mounting an effective immune response toward Leishmania. Naïve Nos $2^{-1-}$ rats did not show any observed abnormalities in the differentiation of $\mathrm{CD}^{+}$ or $\mathrm{CD}^{+} \mathrm{T}$-cell subsets (Supplementary Figure 2), as has previously been reported for NOS2-deficient mice (Wei et al., 1995). Both wild-type and $\mathrm{Nos}^{-/-}$groups of rats were each subcutaneously infected with $10^{7} 1$ amazonensis via the dermal tissue in the ear. Then, peripheral blood mononuclear cells (PBMCs), splenocytes, and mesenteric lymph node (LN) cells were isolated 32 DPI and stimulated with soluble Leishmania antigens (SLA). Culture supernatants were assayed for IFN- $\gamma$ and IL- 4 production by ELISA. Splenocytes and LN cells from both WT and Nos2 $2^{-1-}$ infected rats produced comparable amounts of IFN- $\gamma$, while a significantly higher concentration of IFN- $\gamma$ in PBMCs was detected in the Nos $2^{-1-}$ group than that in the WT group $(p=0.0014$; Figure 3), indicating that $N o s 2^{-1-}$ rats are able to mount a strong Leishmania-specific immune response. The higher level of production of IFN- $\gamma$ in $\mathrm{Nos}^{-/-}$rats is presumably due to the persistence of greater numbers of parasites in the ear dermis, thus eliciting more parasite antigen to be recognized by the immune cells. IL-4 was also detected in both $N o s 2^{-1-}$ and WT rat cells.

Serum cytokines profiles were measured to better understand the immune status in these rats. Inflammatory cytokines were significantly higher in $N o s 2^{-/-}$rats but low to undetectable in WT rats (Figure 4). IFN- $\gamma$, TNF- $\alpha$, IL-12, IL-1 $\beta$, and IL-6 are important pro-inflammatory mediators during tissue inflammation. An increase in these cytokines was observed in the Nos $2^{--}$rats at all the time points tested, indicating that 

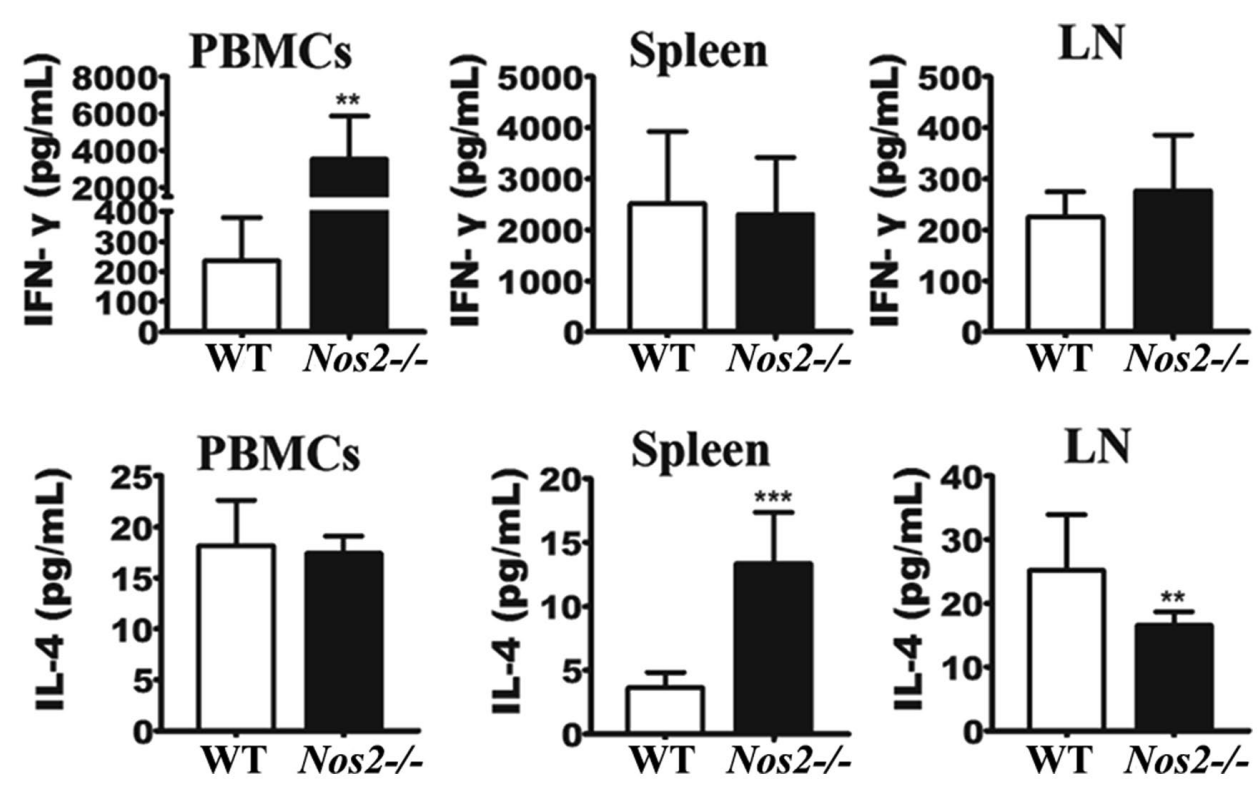

FIGURE 3 | IFN- $\gamma$ and IL-4 production in rat immune cells stimulated with SLA. $2 \times 10^{5} \mathrm{PBMCs}$, LN, and spleen cells were isolated and treated with $50 \mu \mathrm{g} / \mathrm{ml}$ soluble Leishmania antigens (SLA); IFN- $\gamma$ and IL-4 production were determined from culture supernatants at $48 \mathrm{~h}$ post-treatment $(N=6$, mean $\pm \mathrm{SD})$. ${ }^{\star *}$ indicates a significant difference $(0.001<P<0.01)$; $^{\star \star \star}(P<0.001)$.

tissue inflammation persisted and was intense. Furthermore,

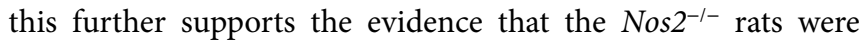
capable of mounting a specific immune response to Leishmania.

\section{Adoptive Transfer of Wild-Type Bone Marrow-Derived Macrophages to Nos2 ${ }^{-/-}$ Rats Delayed Early Lesion Formation and Reduced Parasite Burden}

The above results provided strong evidence for the important role of NOS2 against Leishmania infection in rats. Since the immune regulatory network in $N o s 2^{-/-}$rats is unimpaired, we therefore sought to investigate the role of macrophages in the rat model by adoptive transfer of BMDM from WT rats to

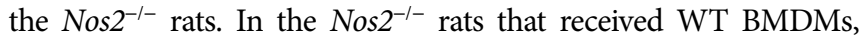
the onset of the lesion development was delayed and shifted from $8 \mathrm{DPI}$ to $16 \mathrm{DPI}$ (Figure 5). Meanwhile, both the lesion thickness and diameter were significantly lower than in the untreated group prior to $20 \mathrm{DPI}$. However, lesions in the treated group developed progressively at a later time point (16-32 DPI). The lesion thickness increased to the same level as the untreated group but the diameter was still lower at 32 DPI. Nevertheless, the $N o s 2^{-1-}$ rats receiving wild-type BMDMs harbored significantly less parasites in lesions compared with the untreated group. These results provided further evidence that macrophages with NOS2 function play an important role in the control of parasites in vivo.

\section{DISCUSSION}

There is a basic question as to why rats are much more resistant to Leishmania spp. infection than mice? Host specificity is a commonly used answer. But what is the mechanism underpinning such specificity? So far as we know, before we started our study, this remained as a black box. To address the question of why rats are much more resistant to pathogen infection than mice, our group previously reported that the high basal NOS2 but low basal arginase activity in rat peritoneal macrophages were linked to their resistance to Toxoplasma infection (Li et al., 2012). Furthermore, results from a comparison of rat alveolar macrophages (sensitive to Toxoplasma infection) with rat peritoneal macrophages (resistant to Toxoplasma infection) showed that this difference was correlated with low and high NOS2 expression, respectively (Zhao et al., 2013). Additionally, differing levels of resistance and susceptibility to T. gondii in different inbred rat strains were correlated with the expression of NOS2 (Gao et al., 2015). More recently, we found that nitric oxide plays a key role in blocking the development of the human parasite Schistosoma japonicum in the rat (Shen et al., 2017). However, arguments still exist about the distinctive differences between Toxoplasma and Leishmania infection. Toxoplasma can infect almost all cells with a nucleus, while Leishmania almost only infects phagocytes but predominantly macrophages.

To exclude the possibility that other mechanisms, rather than L-arginine metabolism, play the key functional role in host specificity, our study used an even more simple model to address this question. As Leishmania infects only macrophages, a Nos2 gene knockout model system can be used to investigate the role of NOS2 in the resistance to Leishmania infection in rats. The importance of macrophage NOS2 in rat resistance to Leishmania has been demonstrated both in vitro and in vivo by the following evidence: 1 . Enhanced intracellular survival and replication of amastigotes in NOS2 inhibited wild-type macrophages or $\mathrm{Nos}^{-/-}$macrophages, 2. inability to eliminate 

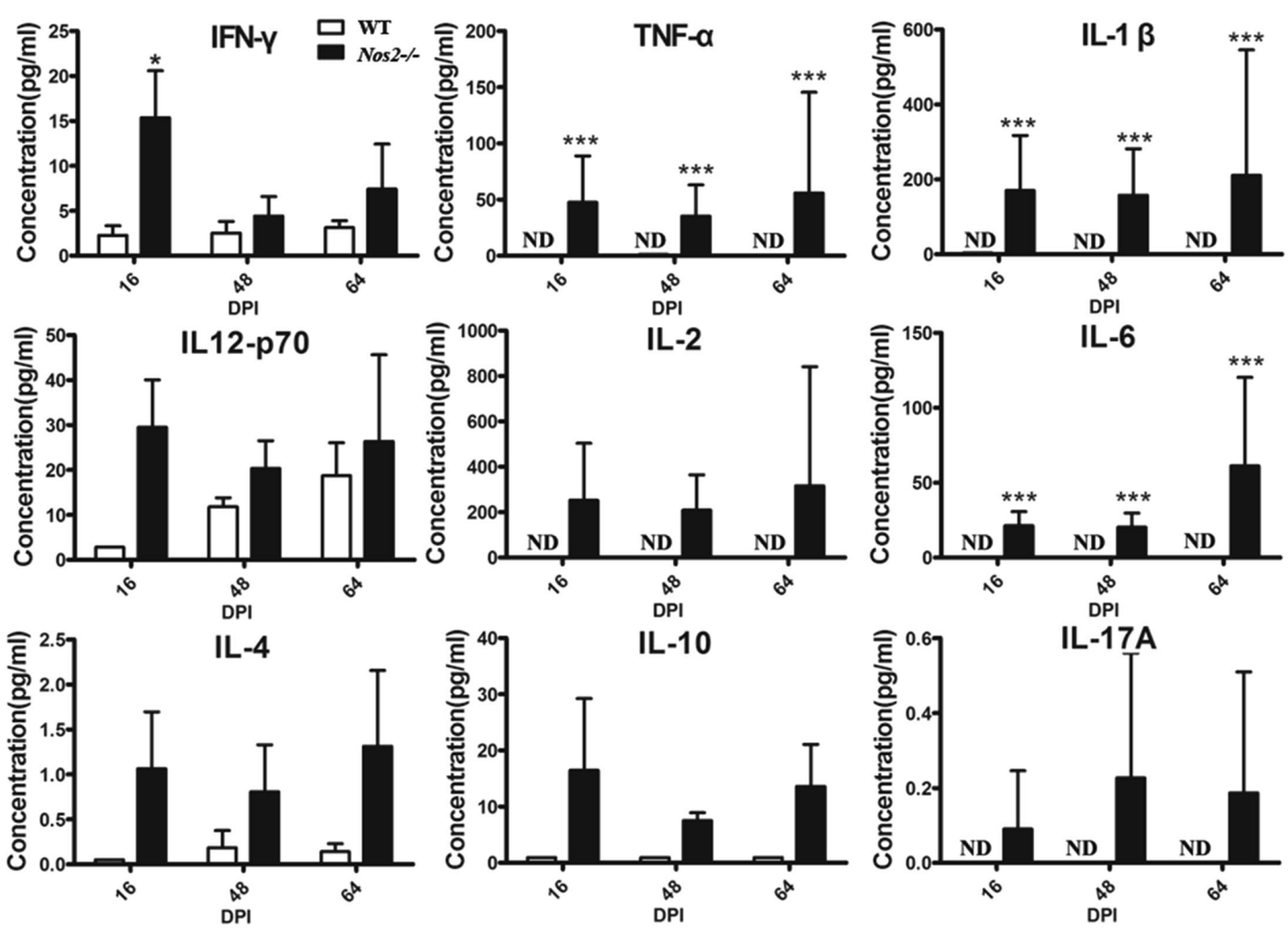

FIGURE 4 | Serum cytokine profiles of rats infected with Leishmania amazonensis. The serum of Nos2 ${ }^{-/-}$and wild-type rats were collected at 16 , 48 , and 64 days postinfection (DPI). Cytokine levels were determined by multiplex Luminex $(N=3$, mean $\pm \mathrm{SD})$. ND: not detectable. ${ }^{*}$ indicates a significant difference $(0.01<P<0.05)$; ${ }^{\star \star *}$ $(P<0.001)$.

amastigotes after activation with IFN- $\gamma$ in Nos2-deficient macrophages, 3. subclinical infection and parasite elimination in wild-type rats compared with progressive lesion development and persistent parasitemia in $N_{o s} 2^{-/-}$rats, even though the immune response was unimpaired, and 4. transfer of macrophages collected from wild-type rats into $\mathrm{Nos}^{-/-}$rats delayed lesion formation and reduced parasite load.

As our data mentioned above clearly show, after infection with an invading pathogen, L-arginine metabolism is key to shaping macrophage function and determines the progression of the disease. Macrophages are major players in the first line of innate defense against many pathogen infections. It is, therefore, fundamental to understand the differences in arginase metabolism in macrophages from various hosts and even between different human populations. Data from Mills and colleagues revealed that macrophages from different mouse strains varied in arginine metabolism in response to immunological stimuli, such as lipopolysaccharide (LPS) or IFN- $\gamma$; thus, they classified macrophages that predominately express NOS2 or arginase pathways as M1 or M2 macrophages, respectively (Mills et al., 2000). However, more striking differences exist between mouse and rat macrophages. When rats are used as a reference, all mouse macrophages, in different inbred lines, were highly polarized toward the M2 state and were characterized by prominent arginase activity and undetectable NOS2 activity (Li et al., 2012). In contrast, naïve macrophages from rat strains were uniformly polarized toward the NOS2 pathway, where arginase activity was low, and thus, they are polarized toward M1 state. More importantly, this polarization is independent of cytokine or microbial product stimulation (Li et al., 2012). Interestingly, other than in the naive state, rat macrophages are also more sensitive to exogenous stimuli than mice macrophages, as they are readily activated at a lower LPS concentrations or produce higher amounts of NO when treated with the same concentration of LPS (Kmonickova et al., 2007). Differential tendencies in arginine utilization were also observed in macrophages during infection. The inducibility of NOS2 activity by LPS was found to be much higher in rat macrophages than mouse macrophages infected with L. amazonensis. Infected rat macrophages produced substantial amounts of $\mathrm{NO}$ at low LPS concentrations, while mouse macrophages required a much higher LPS concentration but only generated limited amounts of NO (Supplementary Figure S3). These findings have pointed to distinctive differences between macrophage potency in generating NO. This may explain why rats, but not mice, are able to control subclinical infections of L. amazonensis and 


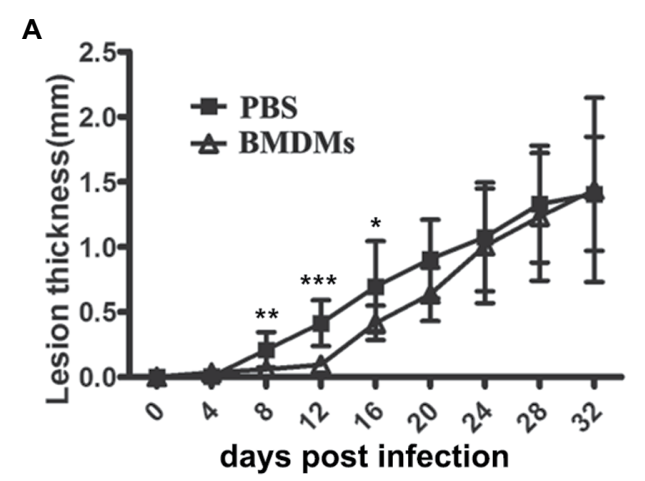

$c$

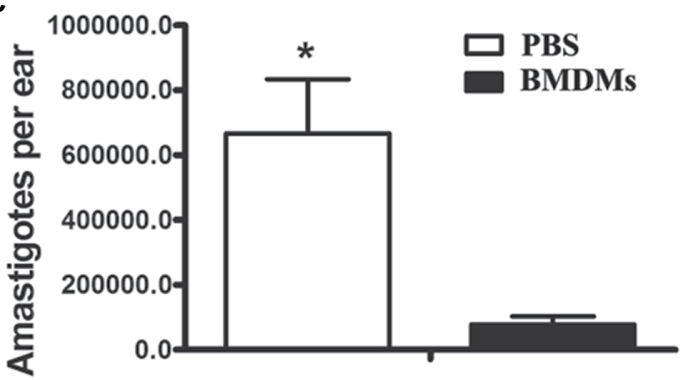

B

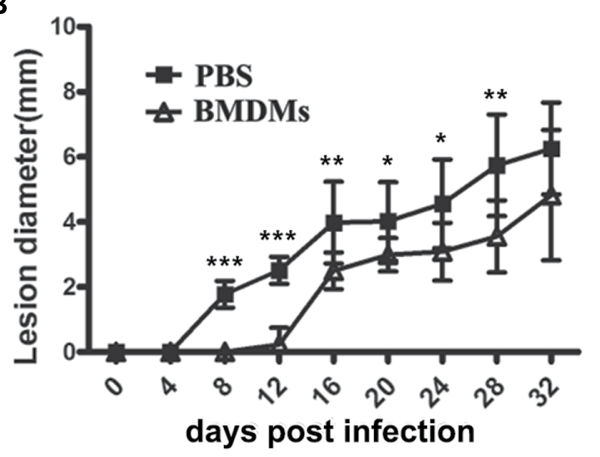

FIGURE 5 | Adoptive transfer of wild-type macrophages to Nos2 ${ }^{-/-}$rats delayed lesion formation and reduced parasite load. Bone marrow cells were isolated from wild-type rats, cultured and differentiated to macrophages (BMDMs) in 30\% L929 cell conditioned medium. Nos $2^{-/-}$rats $(N=5)$ received $3,5,5$, $8 \times 10^{6}$ wild-type rat BMDMs at 0, 8, 16, and 24 days postinfection, respectively. Lesion thickness (A) and diameter (B) were measured every 4 days. (C) Parasite burden (mean \pm SD) on 32 DPI was determined by Limiting dilution assay. * indicates a significant difference $(0.01<P<0.05) ;{ }^{* \star}(0.001<P<0.01)$; ${ }^{* \star \star}(P<0.001)$.

achieve sterile cure. Therefore, this potentially provides a strong mechanistic link to the explanation behind the concept of host specificity. Besides the pivotal role of NOS2, the role of arginase in rat resistance against Leishmania infection remains to be defined. Interestingly, arginase activity is naturally low in rats but high in mice macrophages (Li et al., 2012). High arginase and subsequent polyamine biosynthesis favor parasite survival and replication, and this is a biomarker for active disease status in VL (Iniesta et al., 2002; Kropf et al., 2005; Abebe et al., 2013). Furthermore, evidence has demonstrated that inhibition of arginase activity reduces Leishmania growth and consequent disease development in infected murine hosts (Iniesta et al., 2001, 2005). Taken together, rat macrophages have a propensity to activate the NOS2 pathway during L. amazonensis infection with high NO output accompanied by limited arginase activity. This then creates a highly detrimental microenvironment for Leishmania survival resulting in innate resistance. The disruption of the Nos 2 gene in the knockout rat, and subsequent susceptibility, strongly supports this conclusion. Therefore, we conclude that the host specificity to parasites, at least for Leishmania in rat and mouse models, is mainly due to differences in L-arginine metabolism and polarization toward NOS2 activity.

In our rat model, the deletion of two nucleotides in the Nos2 gene of rats reversed its resistance to Leishmania infection. In view of the long-term co-evolution of host and parasite, the mutation of a single gene is likely to be common and could give rise to different populations that show diversity in gene function. The maintenance of a crucial gene that is responsible for parasite resistance, such as NOS2, is an important selective pressure for the evolution of the host. Any changes in the regulatory pathways that enhance the function of these genes would promote host survival and expansion, especially when the infectious agent is both fatal and present at high prevalence. Rats are, therefore, an extraordinary host that is highly resistant to many pathogen infections. In contrast, gene mutations that weaken or abrogate these genes would favor parasite adaptation to the host, such as occurs in mice and hamsters that are susceptible to infection. The evolution of the Nos 2 gene and its regulatory network in different hosts is extremely interesting, and the importance of this gene is, at least, demonstrated in the rat and mouse. Genomic analysis in the rat has shown that rat-specific genes related to immunity have appeared through an expansion of gene families, which is not seen in the mouse (Gibbs et al., 2004). Further analysis through comparative genomic analysis would be valuable in identifying other genes that confer innate resistance.

In humans, the involvement of NOS2 in protection against leishmaniasis has been demonstrated by the finding that higher NOS2 expression correlates with fewer parasites in localized CL, while low NOS2 expression correlates with high parasite burden in diffuse CL (Qadoumi et al., 2002). In another example, the Tat protein, produced by HIV-1, appears to interfere with protein kinase R (PKR) activity which downregulates NOS2 expression in macrophages derived from healthy human donors and leads to consequent increase in intracellular growth by L. amazonensis 
(Vivarini Ade et al., 2015). Additionally L. amazonensis, itself, may be responsible for down regulation of NOS2 in human and mouse macrophages via the NF- $\kappa \beta$ pathway (Calegari-Silva et al., 2015). Furthermore, NOS2 has been shown to participate in a variety of other human diseases (Kroncke et al., 1998). The question as to whether NOS2 plays a dominant role in human disease is under debate (Albina, 1995; Jungi et al., 1996). There has been some evidence that higher NOS2 activity in humans correlates with protective immunity to infections (Nicholson et al., 1996). For example, in endemic areas with malaria, higher resistance to the disease is present in people with higher NO production in macrophages (Anstey et al., 1996). Thus, by comparison with species differences in rodents, genetic control of differences in NOS2 activity in human populations might also exist. A higher NOS2 activity during infection might also confer protection. Asymptomatic infections of Leishmania in humans have been reported. In infections caused by $L$. infantum, for example, the majority of individuals infected are asymptomatic (Michel et al., 2011). Little is known about the differences in immune status between symptomatic and asymptomatic patients with leishmaniasis. Investigations into the possible involvement of NOS2 might enhance insight into the evolution of the Nos2 gene function and population-related immunity. Based on our findings in the rat model, we suggest that the status of L-arginine metabolism in macrophages reflects host immune function against pathogen infection. High NOS2 activity is a marker for protective response in resistant hosts, while high arginase activity is associated with a suppressed immune response in susceptible hosts.

In summary, the results described here show that a distinctive L-arginine metabolism featuring high NOS2 activity in rat macrophages is responsible for resistance to Leishmania infection. Our data indicate that in addition to the extrinsic factors that shape macrophage function, rat macrophages independently express an innate resistance phenotype to infection. Such inherent properties of the innate immune system are linked to host specificity for parasite infections in various hosts as demonstrated here between rats and mice. This linkage could have important implications for the development of

\section{REFERENCES}

Abebe, T., Takele, Y., Weldegebreal, T., Cloke, T., Closs, E., Corset, C., et al. (2013). Arginase activity - a marker of disease status in patients with visceral leishmaniasis in Ethiopia. PLoS Negl. Trop. Dis. 7:e2134. doi: 10.1371/journal.pntd.0002134

Albina, J. E. (1995). On the expression of nitric oxide synthase by human macrophages. Why no NO? J. Leukoc. Biol. 58, 643-649. doi: 10.1002/jlb.58.6.643

Alexander, J., Satoskar, A. R., and Russell, D. G. (1999). Leishmania species: models of intracellular parasitism. J. Cell Sci. 112, 2993-3002. doi: 10.1242/jcs.112.18.2993

Anstey, N. M., Weinberg, J. B., Hassanali, M. Y., Mwaikambo, E. D., Manyenga, D., Misukonis, M. A., et al. (1996). Nitric oxide in Tanzanian children with malaria: inverse relationship between malaria severity and nitric oxide production/nitric oxide synthase type 2 expression. J. Exp. Med. 184, 557-567. doi: 10.1084/ jem.184.2.557

Barral, A., Petersen, E. A., Sacks, D. L., and Neva, F. A. (1983). Late metastatic Leishmaniasis in the mouse. A model for mucocutaneous disease. Am J Trop Med Hyg 32, 277-285. doi: 10.4269/ajtmh.1983.32.277

Belkaid, Y., Mendez, S., Lira, R., Kadambi, N., Milon, G., and Sacks, D. (2000). A natural model of Leishmania major infection reveals a prolonged "silent" immunotherapy by targeting L-arginine metabolism in leishmaniasis and, perhaps, many other pathogen infections.

\section{DATA AVAILABILITY STATEMENT}

The original contributions presented in the study are included in the article/Supplementary Material, and further inquiries can be directed to the corresponding authors.

\section{ETHICS STATEMENT}

The animal study was reviewed and approved by Institutional Review Board for Animal Care at Sun Yat-Sen University.

\section{AUTHOR CONTRIBUTIONS}

Z-RL, Y-FC, C-YW, S-FY, and D-HL designed the experiment. Y-FC, S-FY, NW, JiS, JuS, J-MG, and Y-ZW did the experiments. Z-RL, Y-FC, S-FY, C-YW, D-HL, and GH analyzed the data. Y-FC, Z-RL, D-HL, and GH wrote the manuscript. All authors approved the final version of the manuscript.

\section{FUNDING}

This work was supported by grants (31720103918 and 31672276) from the National Natural Science Foundation of China to Z-RL, and the Natural Science Foundation of Guangdong Province (2018A030313187) to Y-ZW.

\section{SUPPLEMENTARY MATERIAL}

The Supplementary Material for this article can be found online at: https://www.frontiersin.org/articles/10.3389/fmicb.2021.733286/ full\#supplementary-material

phase of parasite amplification in the skin before the onset of lesion formation and immunity. J. Immunol. 165, 969-977. doi: 10.4049/jimmunol.165.2.969 Boltz-Nitulescu, G., Wiltschke, C., Holzinger, C., Fellinger, A., Scheiner, O., Gessl, A., et al. (1987). Differentiation of rat bone marrow cells into macrophages under the influence of mouse L929 cell supernatant. J. Leukoc. Biol. 41, 83-91. doi: 10.1002/jlb.41.1.83

Calabrese, K. S., and da Costa, S. C. (1992). Enhancement of Leishmania amazonensis infection in BCG non-responder mice by BCG-antigen specific vaccine. Mem. Inst. Oswaldo Cruz 87(Suppl. 1), 49-56. doi: 10.1590/S0074-02761992000500010

Calegari-Silva, T. C., Vivarini, A. C., Miqueline, M., Dos Santos, G. R., Teixeira, K. L., Saliba, A. M., et al. (2015). The human parasite Leishmania amazonensis downregulates iNOS expression via NF-kappaB p50/p50 homodimer: role of the PI3K/Akt pathway. Open Biol. 5:150118. doi: 10.1098/rsob.150118

Chan, M. M., Bulinski, J. C., Chang, K. P., and Fong, D. (2003). A microplate assay for Leishmania amazonensis promastigotes expressing multimeric green fluorescent protein. Parasitol. Res. 89, 266-271. doi: 10.1007/s00436-002-0706-4

Corraliza, I. M., Soler, G., Eichmann, K., and Modolell, M. (1995). Arginase induction by suppressors of nitric oxide synthesis (IL-4, IL-10 and PGE2) in murine bone-marrow-derived macrophages. Biochem. Biophys. Res. Comm. 206, 667-673. doi: 10.1006/bbrc.1995.1094 
Diefenbach, A., Schindler, H., Rollinghoff, M., Yokoyama, W. M., and Bogdan, C. (1999). Requirement for type 2 NO synthase for IL-12 signaling in innate immunity. Science 284, 951-955. doi: 10.1126/science.284.5416.951

Gao, J. M., Yi, S. Q., Wu, M. S., Geng, G. Q., Shen, J. L., Lu, F. L., et al. (2015). Investigation of infectivity of neonates and adults from different rat strains to toxoplasma gondii Prugniaud shows both variation which correlates with iNOS and Arginase-1 activity and increased susceptibility of neonates to infection. Exp. Parasitol. 149, 47-53. doi: 10.1016/j. exppara.2014.12.008

Giannini, S. H. (1985). Induction and detection of leishmanial infections in Rattus norvegicus. Trans. R. Soc. Trop. Med. Hyg. 79, 458-461. doi: 10.1016/0035-9203(85)90064-1

Gibbs, R. A., Weinstock, G. M., Metzker, M. L., Muzny, D. M., Sodergren, E. J., Scherer, S., et al. (2004). Genome sequence of the Brown Norway rat yields insights into mammalian evolution. Nature 428, 493-521. doi: 10.1038/nature02426

Griffiths, M. J., Messent, M., MacAllister, R. J., and Evans, T. W. (1993). Aminoguanidine selectively inhibits inducible nitric oxide synthase. $\mathrm{Br} . J$. Pharmacol. 110, 963-968. doi: 10.1111/j.1476-5381.1993.tb13907.x

Iniesta, V., Carcelen, J., Molano, I., Peixoto, P. M., Redondo, E., Parra, P., et al. (2005). Arginase I induction during Leishmania major infection mediates the development of disease. Infect. Immun. 73, 6085-6090. doi: 10.1128/ IAI.73.9.6085-6090.2005

Iniesta, V., Gomez-Nieto, L. C., and Corraliza, I. (2001). The inhibition of arginase by $\mathrm{N}$ (omega)-hydroxy-l-arginine controls the growth of Leishmania inside macrophages. J. Exp. Med. 193, 777-784. doi: 10.1084/jem.193.6.777

Iniesta, V., Gomez-Nieto, L. C., Molano, I., Mohedano, A., Carcelen, J., Miron, C., et al. (2002). Arginase I induction in macrophages, triggered by Th2-type cytokines, supports the growth of intracellular Leishmania parasites. Parasite Immunol. 24, 113-118. doi: 10.1046/j.1365-3024.2002.00444.x

Jungi, T. W., Adler, H., Adler, B., Thony, M., Krampe, M., and Peterhans, E. (1996). Inducible nitric oxide synthase of macrophages. Present knowledge and evidence for species-specific regulation. Vet. Immunol. Immunopathol. 54, 323-330. doi: 10.1016/S0165-2427(96)05690-5

Kaye, P., and Scott, P. (2011). Leishmaniasis: complexity at the host-pathogen interface. Nat. Rev. Microbiol. 9, 604-615. doi: 10.1038/nrmicro2608

Kmonickova, E., Melkusova, P., Farghali, H., Holy, A., and Zidek, Z. (2007). Nitric oxide production in mouse and rat macrophages: a rapid and efficient assay for screening of drugs immunostimulatory effects in human cells. Nitric Oxide 17, 160-169. doi: 10.1016/j.niox.2007.06.006

Kroncke, K. D., Fehsel, K., and Kolb-Bachofen, V. (1998). Inducible nitric oxide synthase in human diseases. Clin. Exp. Immunol. 113, 147-156. doi: 10.1046/j.1365-2249.1998.00648.x

Kropf, P., Fuentes, J. M., Fahnrich, E., Arpa, L., Herath, S., Weber, V., et al. (2005). Arginase and polyamine synthesis are key factors in the regulation of experimental leishmaniasis in vivo. FASEB J. 19, 1000-1002. doi: 10.1096/fj.04-3416fje

Li, Z., Zhao, Z. J., Zhu, X. Q., Ren, Q. S., Nie, F. F., Gao, J. M., et al. (2012). Differences in iNOS and arginase expression and activity in the macrophages of rats are responsible for the resistance against T. gondii infection. PLoS One 7:e35834. doi: 10.1371/journal.pone.0035834

Liew, F. Y., Li, Y., Moss, D., Parkinson, C., Rogers, M. V., and Moncada, S. (1991). Resistance to Leishmania major infection correlates with the induction of nitric oxide synthase in murine macrophages. Eur. J. Immunol. 21, 3009-3014. doi: 10.1002/eji.1830211216

MacMicking, J., Xie, Q. W., and Nathan, C. (1997). Nitric oxide and macrophage function. Annu. Rev. Immunol. 15, 323-350. doi: 10.1146/annurev. immunol.15.1.323

Melby, P. C., Chandrasekar, B., Zhao, W., and Coe, J. E. (2001). The hamster as a model of human visceral leishmaniasis: progressive disease and impaired generation of nitric oxide in the face of a prominent Th1-like cytokine response. J. Immunol. 166, 1912-1920. doi: 10.4049/jimmunol.166.3.1912

Michel, G., Pomares, C., Ferrua, B., and Marty, P. (2011). Importance of worldwide asymptomatic carriers of Leishmania infantum (L. chagasi) in human. Acta Trop. 119, 69-75. doi: 10.1016/j.actatropica.2011.05.012

Mills, C. D., Kincaid, K., Alt, J. M., Heilman, M. J., and Hill, A. M. (2000). M-1/M-2 macrophages and the Th1/Th2 paradigm. J. Immunol. 164, 61666173. doi: $10.4049 /$ jimmunol.164.12.6166

Muller, I., Pedrazzini, T., Farrell, J. P., and Louis, J. (1989). T-cell responses and immunity to experimental infection with leishmania major. Annu. Rev. Immunol. 7, 561-578. doi: 10.1146/annurev.iy.07.040189.003021
Murray, H. W., Berman, J. D., Davies, C. R., and Saravia, N. G. (2005). Advances in leishmaniasis. Lancet 366, 1561-1577. doi: 10.1016/ S0140-6736(05)67629-5

Nicholson, S., Bonecini-Almeida, M. G., Lapa e Silva, J. R., Nathan, C., Xie, Q. W., Mumford, R., et al. (1996). Inducible nitric oxide synthase in pulmonary alveolar macrophages from patients with tuberculosis. J. Exp. Med. 183, 2293-2302. doi: 10.1084/jem.183.5.2293

Perez, L. E., Chandrasekar, B., Saldarriaga, O. A., Zhao, W., Arteaga, L. T., Travi, B. L., et al. (2006). Reduced nitric oxide synthase 2 (NOS2) promoter activity in the Syrian hamster renders the animal functionally deficient in NOS2 activity and unable to control an intracellular pathogen. J. Immunol. 176, 5519-5528. doi: 10.4049/jimmunol.176.9.5519

Qadoumi, M., Becker, I., Donhauser, N., Rollinghoff, M., and Bogdan, C. (2002). Expression of inducible nitric oxide synthase in skin lesions of patients with american cutaneous leishmaniasis. Infect. Immun. 70, 4638-4642. doi: 10.1128/IAI.70.8.4638-4642.2002

Rittig, M. G., and Bogdan, C. (2000). Leishmania-host-cell interaction: complexities and alternative views. Parasitol. Today 16, 292-297. doi: 10.1016/ S0169-4758(00)01692-6

Sacks, D., and Noben-Trauth, N. (2002). The immunology of susceptibility and resistance to Leishmania major in mice. Nat. Rev. Immunol. 2, 845-858. doi: $10.1038 /$ nri933

Saldarriaga, O. A., Travi, B. L., Choudhury, G. G., and Melby, P. C. (2012). Identification of hamster inducible nitric oxide synthase (iNOS) promoter sequences that influence basal and inducible iNOS expression. J. Leukoc. Biol. 92, 205-218. doi: 10.1189/jlb.1010568

Shen, J., Lai, D. H., Wilson, R. A., Chen, Y. F., Wang, L. F., Yu, Z. L., et al. (2017). Nitric oxide blocks the development of the human parasite Schistosoma japonicum. Proc. Natl. Acad. Sci. USA 114, 10214-10219. doi: 10.1073/ pnas. 1708578114

Soong, L. (2012). Subversion and utilization of host innate defense by Leishmania amazonensis. Front. Immunol. 3:58. doi: 10.3389/fimmu.2012.00058

Soong, L., Chang, C. H., Sun, J., Longley, B. J. Jr., Ruddle, N. H., Flavell, R. A., et al. (1997). Role of CD4+ T cells in pathogenesis associated with Leishmania amazonensis infection. J. Immunol. 158, 5374-5383.

Stenger, S., Thuring, H., Rollinghoff, M., and Bogdan, C. (1994). Tissue expression of inducible nitric oxide synthase is closely associated with resistance to Leishmania major. J. Exp. Med. 180, 783-793. doi: 10.1084/jem.180.3.783

Taylor-Robinson, A. W., Liew, F. Y., Severn, A., Xu, D., McSorley, S. J., Garside, P., et al. (1994). Regulation of the immune response by nitric oxide differentially produced by $\mathrm{T}$ helper type 1 and $\mathrm{T}$ helper type 2 cells. Eur. J. Immunol. 24, 980-984. doi: 10.1002/eji.1830240430

Tesson, L., Usal, C., Menoret, S., Leung, E., Niles, B. J., Remy, S., et al. (2011). Knockout rats generated by embryo microinjection of TALENs. Nat. Biotechnol. 29, 695-696. doi: 10.1038/nbt.1940

Vasconcellos, C., and Sotto, M. N. (1997). Experimental cutaneous leishmaniasis: transmission electron microscopy of the inoculation site. Int. J. Exp. Pathol. 78, 81-89. doi: 10.1046/j.1365-2613.1997.d01-243.x

Vivarini Ade, C., Santos Pereira Rde, M., Barreto-de-Souza, V., Temerozo, J. R., Soares, D. C., Saraiva, E. M., et al. (2015). HIV-1 tat protein enhances the intracellular growth of Leishmania amazonensis via the ds-RNA induced protein PKR. Sci. Rep. 5:16777. doi: 10.1038/srep16777

Wei, X. Q., Charles, I. G., Smith, A., Ure, J., Feng, G. J., Huang, F. P., et al. (1995). Altered immune responses in mice lacking inducible nitric oxide synthase. Nature 375, 408-411. doi: 10.1038/375408a0

World Health Organization (2010). Control of the leishmaniases. World Health Organ. Tech. Rep. Ser. 949, 1-186.

Zhao, Z. J., Zhang, J., Wei, J., Li, Z., Wang, T., Yi, S. Q., et al. (2013). Lower expression of inducible nitric oxide synthase and higher expression of arginase in rat alveolar macrophages are linked to their susceptibility to toxoplasma gondii infection. PLoS One 8:e63650. doi: 10.1371/journal.pone.0063650

Conflict of Interest: The authors declare that the research was conducted in the absence of any commercial or financial relationships that could be construed as a potential conflict of interest.

Publisher's Note: All claims expressed in this article are solely those of the authors and do not necessarily represent those of their affiliated organizations, or those of the publisher, the editors and the reviewers. Any product that may 
be evaluated in this article, or claim that may be made by its manufacturer, is not guaranteed or endorsed by the publisher.

Copyright $\odot 2021$ Chen, Yu, Wu, Wu, Shen, Shen, Gao, Wen, Hide, Lai and Lun. This is an open-access article distributed under the terms of the Creative Commons
Attribution License (CC BY). The use, distribution or reproduction in other forums is permitted, provided the original author(s) and the copyright owner(s) are credited and that the original publication in this journal is cited, in accordance with accepted academic practice. No use, distribution or reproduction is permitted which does not comply with these terms. 